\title{
LIGHTWEIGHT UHPC FACADE PANEL WITH LED DISPLAY
}

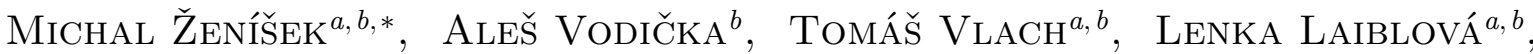 \\ PETR HÁJeK ${ }^{a, b}$ \\ ${ }^{a}$ Czech Technical University in Prague, Faculty of Civil Engineering, Thákurova 7, 166 29 Prague 6, Czech \\ Republic \\ ${ }^{b}$ Czech Technical University in Prague, University Centre for Energy Efficient Buildings, Třinecká 1024, 27343 \\ Buštěhrad, Czech Republic \\ * corresponding author: michal.zenisek@fsv.cvut.cz
}

\begin{abstract}
This article deals with the development of lightweight UHPC facade panel which also can serve as an LED display. Combining both functions into one gives the potential ability to create a LED display on the facade of the building. The article describes the experiences of the development and production of a small-format prototype facade panel, including the installation of LEDs and their electrical connection. The result of the research is the prototype of a $16 \mathrm{~mm}$ thick small-format lightweight facade panel with a LED display for displaying text on two parallel lines. Thanks to the waffle lightening, the total material and weight savings are approximately $58 \%$ compared with the full cross section.
\end{abstract}

KEYwORDS: Facade panel, UHPC, LED diodes, LED display.

\section{INTRODUCTION}

Ultra-high performance concrete (UHPC) is cement composite that is characterized by very high strength and long durability. These two benefits make UHPC an excellent material that can be used across a wide range of applications from the field of construction and architecture. On the other hand, the UHPC price is several times higher than conventional concrete and therefore its use is reserved for the most demanding buildings or for buildings where long durability is expected. Very often, the UHPC does not make the entire construction, but only the part which is most suitable for UHPC use. As an example, it can be mentioned joints of prefabricated elements, thin facade elements, staircases, balconies, etc.

Structures and products from UHPC are characterized by their subtle design [1. This is possible due to high strength, but also due to other specific properties. The maximum aggregate size is very small in the most UHPC mixtures and does not limit the reinforcement or shape of the element. Conventional steel reinforcement can be replaced by alternative reinforcement methods, for example by using technical textiles or dispersed reinforcement (fibres, microfibres) 2]. The high cement content and low porosity can better protect reinforcement against corrosion and it is therefore possible to reduce the cover depths of reinforcement. All these features make it possible to reduce the dimensions of UHPC elements. To sum up, the element's self-weight will decrease as well as price due to lower material consumption [3].

The production of thin UHPC panels has been very popular lately. The main effort of most manufacturers remains to achieve the required properties while main- taining the minimum weight of the panel. Nowadays, the facade panels with a thickness of $9 \mathrm{~mm}$ can be seen [4. However, reducing the thickness cannot be done indefinitely, and therefore other methods are also successfully used to reduce the weight of the panel. An example may be lightening the panel with polystyrene [5] or reinforcement with ribs [6].

\section{PANEL DESCRIPTION AND ITS PRODUCTION}

This paper deals with lightweight facade panel with dimensions of $500 \times 600 \mathrm{~mm}$ from UHPC with LED display. Lightening is realized by weakening the panel to $5 \mathrm{~mm}$ on the front and reinforcing with $11 \mathrm{~mm}$ high ribs on the back. The reinforcing ribs are conical, 6-9 $\mathrm{mm}$ thick and are oriented in two perpendicular directions with an axial distance of $50 \mathrm{~mm}$. The space between ribs is used to fit LEDs (Light Emitting Diodes) in a regular raster of $16.7 \mathrm{~mm}$, interconnecting them and creating an LED display. Compared to the full cross section, the material and weight savings are more than $58 \%$. The overall geometry of the panel can be seen from the section in Figure 1 .

The shape of the panel was optimized during development. The resulting solution is a compromise between the various requirements during production and subsequent placement on the facade. In the first place, it is necessary to ensure sufficient stiffness of the panel against wind load. Therefore, the distance of the ribs cannot be too large to provide sufficient stiffness, but not too small to achieve the highest degree of lightening. The location of the ribs also strongly affects the way of panel reinforcement. It was considered using both dispersed reinforcement (fi- 


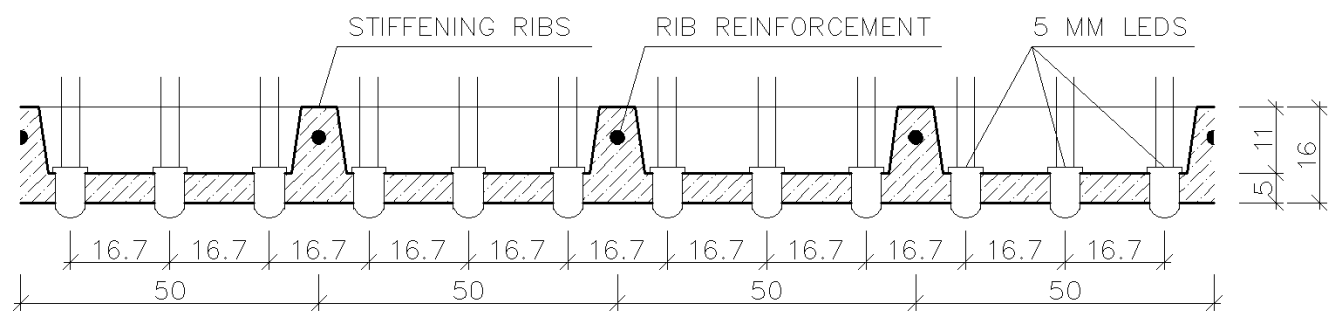

Figure 1. Panel section.

\begin{tabular}{lcc}
\hline Material & {$\left[\mathrm{kg} / \mathrm{m}^{3}\right]$} & $\begin{array}{c}\text { Proportions } \\
\text { by weight }\end{array}$ \\
\hline Cement 42.5 R & 650 & 1 \\
Microsilica & 40 & 0.06 \\
Quartz sand 0/0.6 mm & 1200 & 1.85 \\
Quartz powder & 250 & 0.38 \\
Superplasticizers & 25 & 0.04 \\
Water & 182 & 0.28 \\
\hline
\end{tabular}

TABLE 1. Used mixture.

bres, microfibres) and textile reinforcement which also proved to be more appropriate. Its main advantage is to ensure a higher stiffness of the panel and a uniform quality of reinforcement. In case of using dispersed reinforcement, it is possible to create ribs of any shape, but with a high fibres content $\left(120 \mathrm{~kg} / \mathrm{m}^{3}\right)$ the overall bending stiffness is significantly smaller. Other disadvantages include deterioration of workability and the risk of uneven reinforcement. For these reasons, the use of textile reinforcement has been preferred.

At the beginning of the research, textile reinforcements from glass, carbon and basalt were tested [6]. These reinforcements had to be manually manufactured for research purposes (the textile was weaved) because commercially available products did not match the shape of the panel. The axial distance ribs as well as LEDs were in the first variant $24 \mathrm{~mm}$ (i.e. only one LED was placed between the ribs). This spacing of the LEDs would require a large distance from the viewer. For these reasons, a new solution has been sought which resulting in an axial distance of $50 \mathrm{~mm}$ for ribs and $16.7 \mathrm{~mm}$ for LEDs (Fig. 1). The axial distance of the $50 \mathrm{~mm}$ ribs was chosen intentional because excluding textile reinforcements that would have to be hand-made again, it was possible to use commercially available steel welded mesh. This has proved to be the best, both in terms of price and production.

The UHPC mixture was gradually tuned to the final form during development (Table 1). The most important task was to achieve a high degree of consistency so that the panel surface was sufficiently smooth and the ribs were correctly concreted. On the contrary, the high strength of the UHPC is not so necessary for the functionality of the panel because the panel will be stressed on the facade mainly by bending which is ensured by reinforcement. The $\mathrm{w} / \mathrm{c}$ ratio of the mixture was therefore adjusted from the usual values of 0.25 to 0.28 and the content of cement and microsilica was reduced. It was also essential to use only small aggregate size (again due to the correct concreting of the ribs) and therefore quartz sand with a maximum grain size of $0.6 \mathrm{~mm}$ was used.

The panel was produced by casting UHPC into the mould and short vibration on the vibrating table. The panel was oriented upward during the casting and due to the high degree of consistency, it was not necessary to modify the view side (Fig. 2). The reinforcement was inserted into the mould before casting and a short vibration ensured reliable filling of the ribs with concrete. The opposite approach, pushing the reinforcement into the concrete after casting has also been tested. However, this approach was not very successful due to the high viscosity of the UHPC mixture, which prevented the pushing of the reinforcement.

Fixing the LEDs to the panel was preceded the creation of holes for the LEDs. These could be set up in the panel in two ways: using a special punch during casting or cutting through a water jet on a hardened specimen. The first way, the special punch is driven into the panel during casting and will pull out after several hours when the mixture begins to harden. This solution is very cheap, but it puts increased demands on the precise location of the punch during casting. In contrast, the second way, the cutting of water jet is much more expensive, but the resulting quality of the holes is at a higher level.

The LEDs with a diameter of $5 \mathrm{~mm}$ were then placed in the holes and fixed by the hot-melt adhesive. The advantage of this solution is the possibility of easy repairs when necessary because hot-melt adhesive can be relatively easily removed. For these reasons, the epoxy resin proved to be inappropriate because it cannot be removed and can pass through holes around LEDs.

\section{LED DISPLAY}

The LED panel has 2 sections located one under the other, each consisting of 10 rows and 32 columns. Therefore, there are 20 rows and 32 columns in total (Fig. 3 and 4). Every single row and column are represented by a wire, which is isolated from the others. 

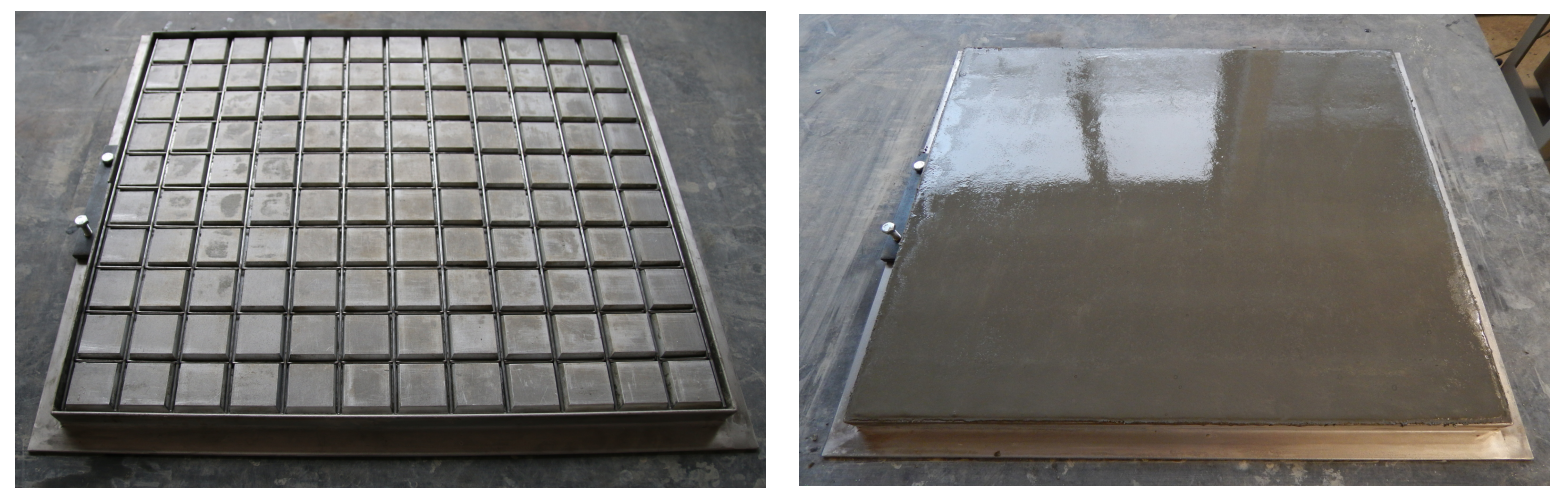

FIGURE 2. Ready mould (left), mould after casting (right).

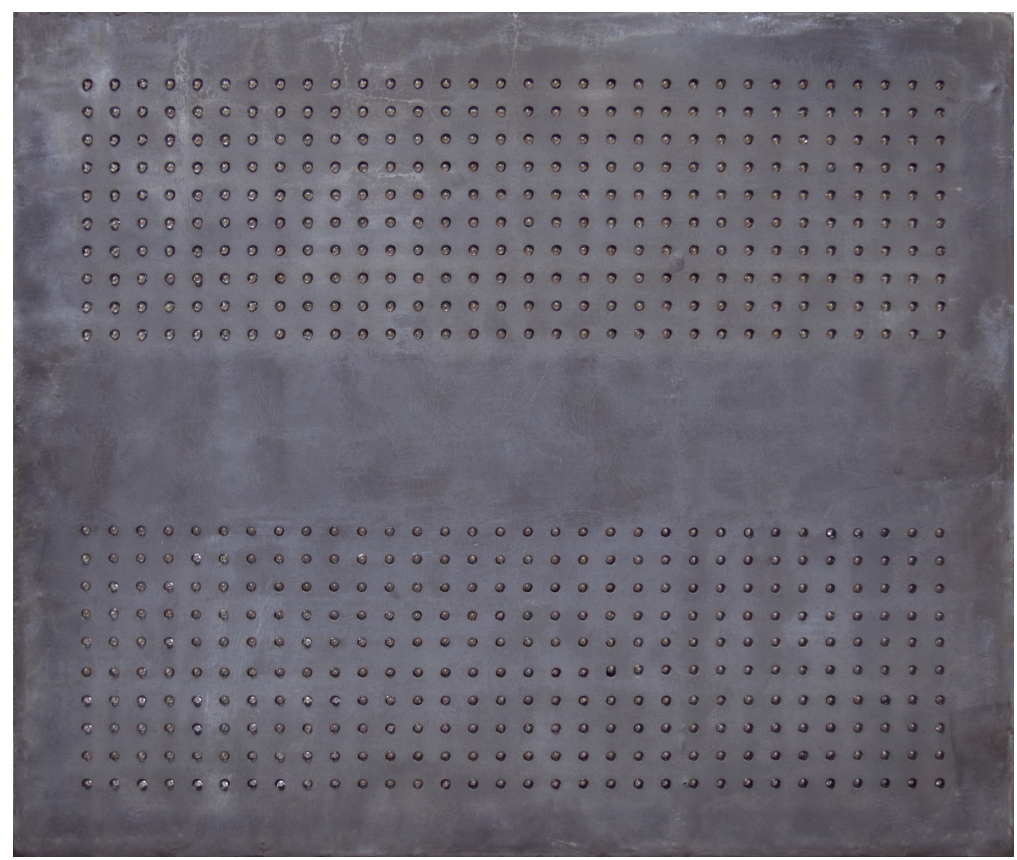

Figure 3. Front side of panel.

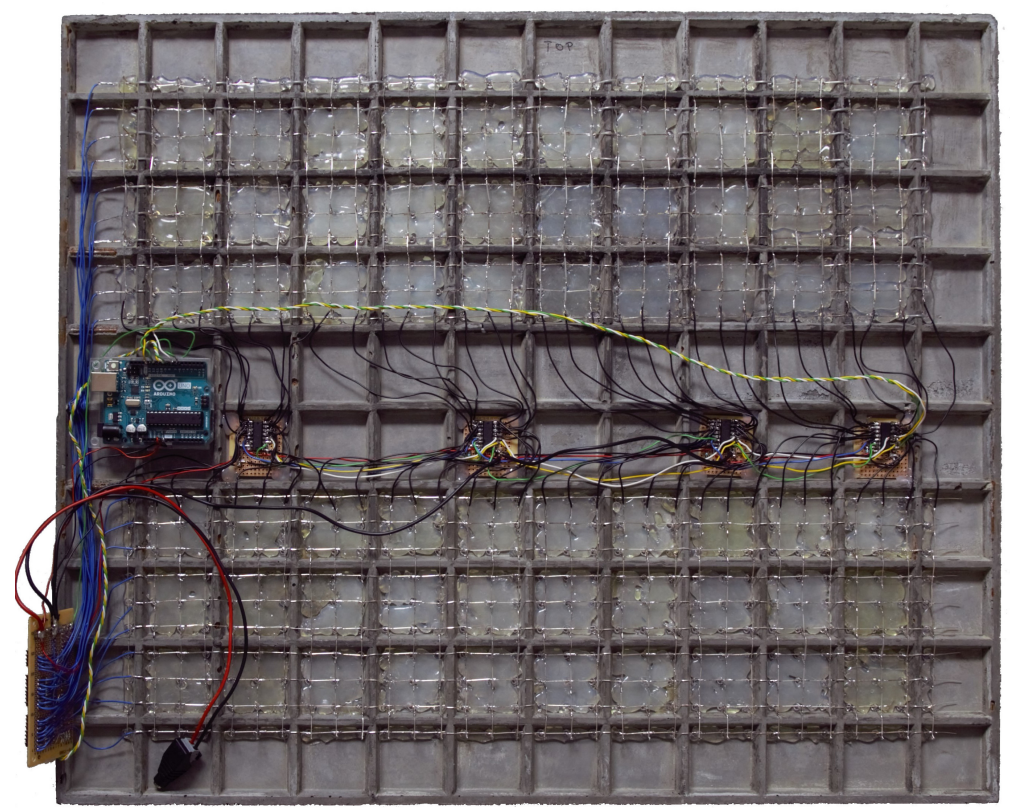

Figure 4. Back side of panel. 


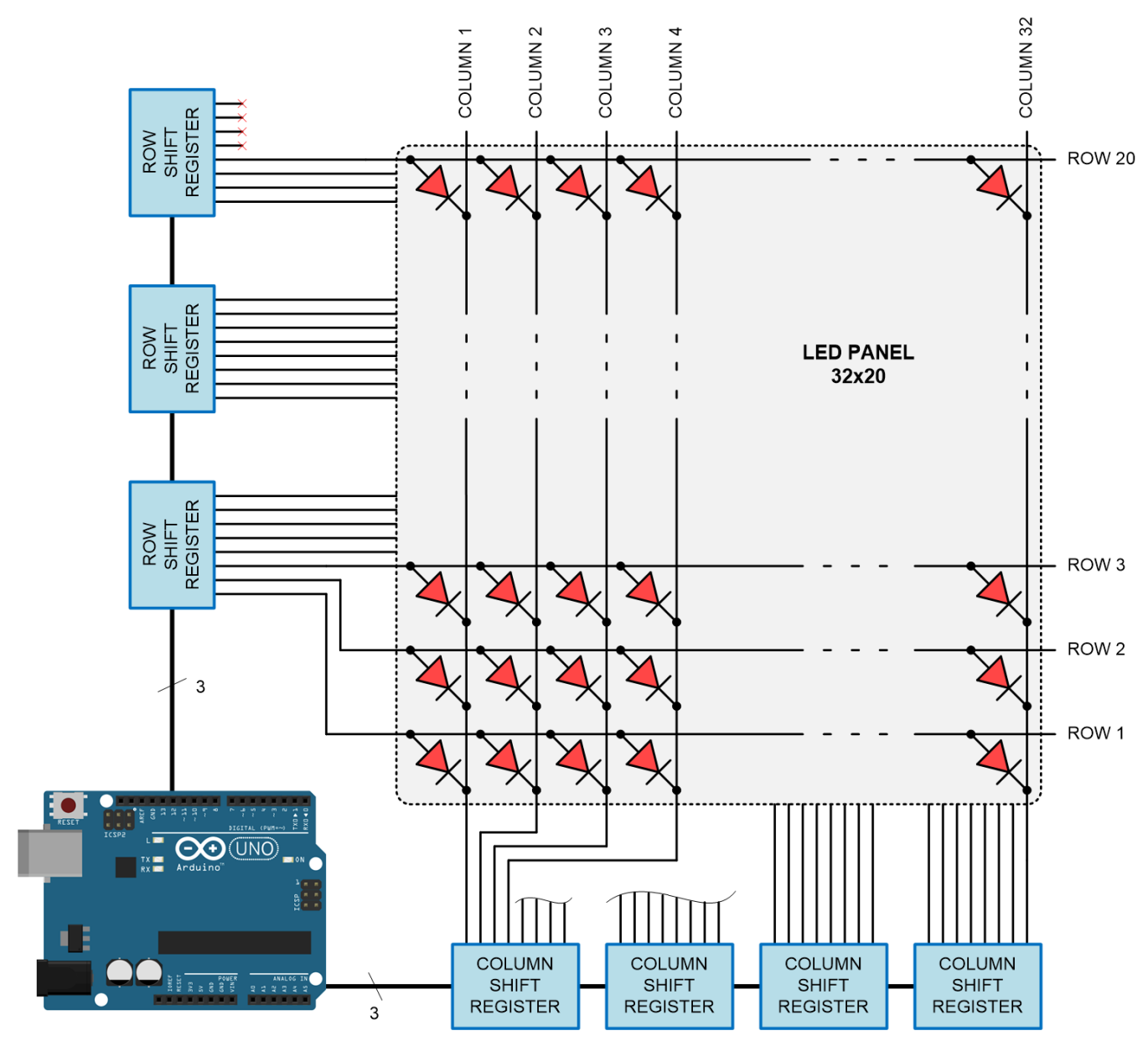

Figure 5. Block diagram of LED panel.

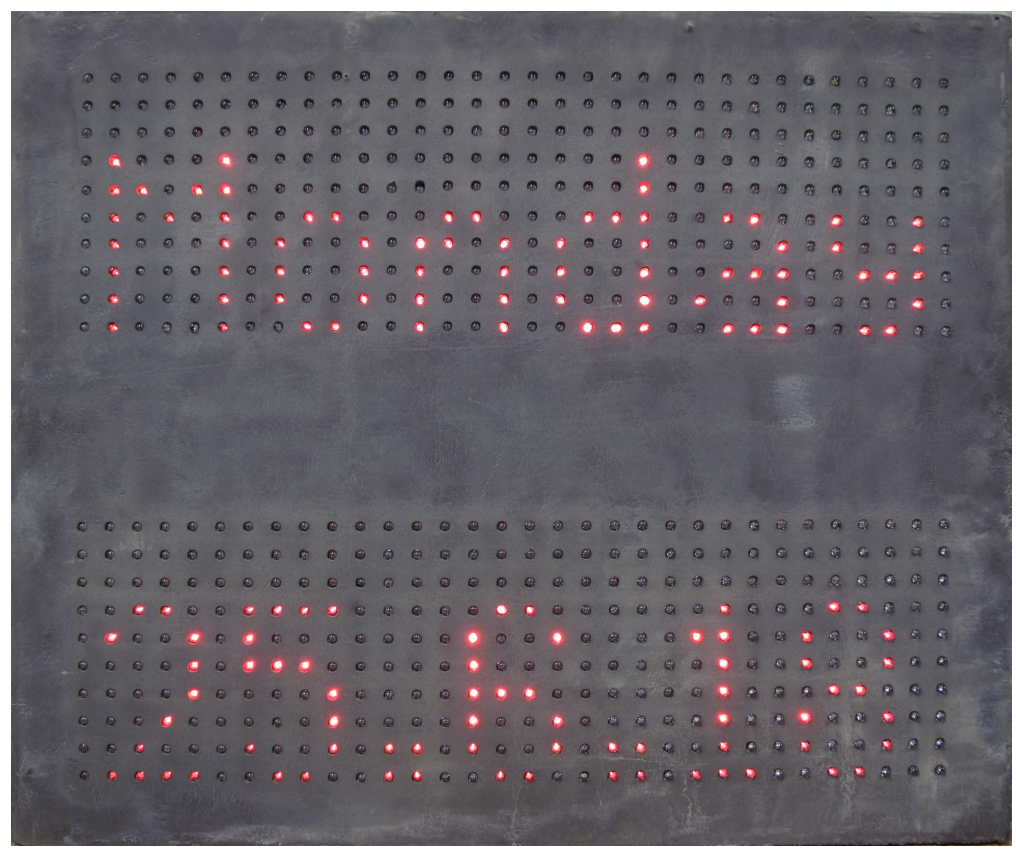

FIGURE 6. Lit LED panel. 
At every crossing of row and column conductor there is LED which has one lead (anode - positive) connected to the row conductor and the other lead (cathode negative) to the column conductor. In total, there are 640 LEDs connected into a matrix form.

The matrix display allows controlling the individual LEDs (pixels) by activating particular row and column. It is also possible to turn on multiple pixels simultaneously as long as the pixels are in the same row or column. Displayed content is being drawn sequentially row by row and every row is active only for $1 \mathrm{~ms}$ (time division multiplex). The full display is then formed in $20 \mathrm{~ms}$. This row switching repeats infinitely to keep the content of the display visible. The switching process is not noticeable to an observer, since human eye is relatively slow and is not capable to see such fast transitions.

Continuous current consumption of single LED is maximally $20 \mathrm{~mA}$. Time division multiplex keeps the LED on only for $1 / 20$ of the whole image time. This will obviously affect the brightness of LED. The LED can be overloaded up to five times $(100 \mathrm{~mA})$ for a very short time, thus brightness drop can be compensated. Even though the achieved brightness is still lower than the maximal possible, it is still good enough to ensure good readability of the display. The whole display assembly is powered from $5 \mathrm{~V}$ power supply. The maximal current consumption of all LEDs on at maximal brightness is $3.2 \mathrm{~A}$; that gives the total power consumption $16 \mathrm{~W}$ (consumption of electronics is negligible in comparison with the display).

Arduino UNO microcontroller controls the matrix display (Fig. 5). The additional electronics had to be developed for Arduino UNO in order to connect all the LEDs since this platform does not have enough output pins to connect all the rows (20) and all the columns (32). The electronics uses shift registers to convert serial information to parallel allowing the direct connection to rows/columns. Every shift register has 8 outputs so connection of several shift registers in series is needed to serve all the lines while requiring only 3 output pins of Arduino UNO. There are 3 shift registers controlling the rows and 4 shift registers controlling the columns.

Software controlling the Arduino Uno was written in $\mathrm{C}$ programming language. Code contains repertoire of characters for easy letters and digits displaying. There is text string being stored in the memory of microcontroller, which is being displayed on 2 lines of LED panel. The text scrolls from right to left in case the string is longer than the width of the panel. The versatility of this solution allows easy extension in the future, such as displaying the current date and time (Fig. 6) or information from a superior system.

\section{Summary}

The subject of this research was the development and experimental fabrication of a small format prototype lightweight UHPC facade panel with LED display. The main effort was to find an optimal shape between sufficient stiffness, easy rib reinforcement and the densest distribution of LEDs forming the LED display. The resulting panel has dimensions of $500 \times 600 \mathrm{~mm}$ with a total thickness of $16 \mathrm{~mm}$ ( $5 \mathrm{~mm}$ plate, $11 \mathrm{~mm}$ ribs) and $50 \mathrm{~mm}$ axial spacing. Thanks to this solution, compared to the full cross section, the material and weight savings are more than $58 \%$. The LED display consists of two parallel fields for displaying text. The LED display function is controlled by the Arduino UNO microcontroller, which has been specially programmed for this purpose.

\section{ACKNOWLEDGEMENTS}

The authors thank University Centre for Energy Efficient Buildings CTU in Prague for provision of laboratories for experimental work. This work has been supported by the Ministry of Education, Youth and Sports within National Sustainability Programme I, project No. LO1605 and by the TACR 11124311 3111702A124 Subtle Concrete Furniture and Small Structures for the Railways Stations.

\section{REFERENCES}

[1] E. Vicenzino, V. Perry, T. Chow, et al. First use of UHPFRC in thin precast concrete roof shell for Canadian LRT station. PCI Journal 50:50-67, 2005. DOI:10.15554/pcij.09012005.50.67.

[2] K. Hannawi, H. Bian, W. Prince-Agbodjan, B. Raghavan. Effect of different types of fibers on the microstructure and the mechanical behavior of ultra-high performance fiber-reinforced concretes. Composites Part B: Engineering 86:214-220, 2016. DOI:10.1016/j.compositesb.2015.09.059

[3] M. Robentrost, G. Wight. Experience and applications of ultra-high performance concrete in Asia. In Proceedings of Second International Symposium on Ultra High Performance Concrete, pp. 19-30. 2008.

[4] G.tecz Engineering GmbH. https://www.gtecz-engineering.com/

[5] A. Chira, A. Kumar, T. Vlach, et al. Textile-reinforced concrete facade panels with rigid foam core prisms. Journal of Sandwich Structures and Materials 18:200-214, 2015. DOI:10.1177/1099636215613488.

[6] L. Laiblová, T. Vlach, M. Ženíšek, et al. Lightweight TRC facade panels with the LEDs. In Special Concrete and Composites 2017, vol. 760 of Key Engineering Materials, pp. 141-146. Trans Tech Publications, 2018. DOI:10.4028/www.scientific.net/KEM.760.141 